\title{
A Constructivist Approach to Saudi Arabia's Accession and Compliance to the WTO
}

\author{
Nan Cheng ${ }^{1, *, \dagger}$, Fei Duan ${ }^{2, \dagger}$, Anqi Wang ${ }^{3, \dagger}$, Ruoxin Wang $^{4, \dagger}$ \\ ${ }^{1}$ Nottingham Ningbo University, Ningbo, Zhejiang, China \\ ${ }^{2}$ McGill University, Montreal, Quebec, Canada \\ ${ }^{3}$ Sun Yat-sen University, Guangzhou, Guangdong, China \\ ${ }^{4} X i$ 'an Jiaotong-Liverpool University, Suzhou, Jiangsu, China \\ ${ }^{*}$ Corresponding author. Email: ${ }^{1}$ hiync1@nottingham.edu.cn, ${ }^{2}$ fei.duan@mail.mcgill.ca, \\ ${ }^{3}$ wanganq7@mail.sysu.edu.cn, ${ }^{4}$ Ruoxin.wang19@student.xjtlu.edu.cn \\ Those authors contributed equally.
}

\begin{abstract}
After a tardy, dilatory negotiation for more than twelve years, the WTO (formerly known as the GATT) had finally accepted Saudi Arabia's accession request in 2005. The essay aims to explain Saudi Arabia's accession to WTO through the theory of constructivism with studies of several cases. The authors firstly introduce constructivism as a theoretical approach to explain Saudi Arabia's accession, and then demonstrate empirical studies including Saudi Arabia's compliance to WTO and disputes declare a "dual identity" quality considering its national conditions. Ultimately, according to constructivism, the essay draws the conclusion that Saudi Arabia's prospect in WTO could be expectable, as well as unpredictable.
\end{abstract}

Keywords: Saudi Arabia, WTO, 2005, Constructivism, Social Identity, Islam.

\section{INTRODUCTION}

Our research aims to develop a further argument on the Saudi Arabia's accession and compliance to WTO through constructivism. This research question is puzzling because Saudi is a complete monarchy system. This king of the authoritarian political system could hamper globalization from its internal factors. However, Saudi's desire to joining WTO is supported by the ruling family. Hence, we are keen to analysing what factor drive Saudi's accession to WTO with its especial IPE system.

The essay is divided into five main sections. After the introduction, the essay will examine the theoretical review about why a nation joins the international institution through constructivism. The next section provides its basic IPE characters, which may provide a foundation to explain the factors. The third part of the discussion will look at the constructivism approach on the case of Saudi Arabia to explain the reason for joining in WTO. The essay will then offer an analysis of the empirical example about Saudi Arabia include the accession and compliance to WTO. Finally, the essay will subsequently predict the prospect of Saudi Arabia's accession. The conclusion will firstly conclude the main arguments that have been set and then will emphasizes the importance of doing this research, which will reflect on the limitations of our arguments and finally suggests the further future direction of our arguments.

\section{THEORETICAL REVIEW}

Basiccaly, constructivism offers us the approach to analyse Saudi's accession to the WTO. This section begins with what drives a nation to participate in the IOs through this kind of theory. Firstly, a state join in IOs is influenced by its idea, interest, and identity. Karraboo claims that they are constructed from various understandings associated with different norms and cultures [1]. Thus, it becomes important to understand how a state or a society conceives of itself and its interests, rather than simply asserting that all states are the same. For joining IOs, constructivist thinks nation join in IOs is focused on their own interests, a state's interest is the product of the collective social context of global politics form their identity [1]. Therefore, their interests were influenced by their identity and constantly changing, there is a reciprocal transformation between the logic of consequence and the logic of appropriation. 
Differ from liberalism claims, states joining the IOs because the foreign policy is shaped by the public preferences, but the constructivism thinks the interests are fixed by the identities of actors and pay attention to the individual. Especially in an authoritarian country, the preferences of domestic politics are performed by the level of political elites. Leaders' preferences and decisions are equally important in shaping norms because their decision of significance to their ruling legitimacy. In this case, the scholar like Bello claims that preferences are not simply driven by economic benefits or increasing power. Islamic cultural identity determined what was considered unacceptable behaviour and practice from the ruling family [2]. For Saudi, the cultural norms have shaped the national identity toward making foreign policy and these are determined by the King for strengthening collective identity. In the meantime, Checkel urges institutions as sites of socialization for individuals [3]. Via a process of social learning, state agents may learn new roles and interests from the start and in the absence of social mobilization.

Another point is the international institutions are social environments, the state can internalize specific norms and rules in the process of socialization through joining IOs. For constructivism, international institutions are more than just instruments or arenas. They both reflect the values and norms of their members but also influence the values and norms of their members. International institutions thus have an impact on how states see the world impact on behavior and interests of states. According to Checkel, institutions serve as promoters of socialization in public arenas [3]. In adopting community rules, socialization implies that an agent switches from following a logic of consequences to a logic of appropriateness. Mohammadzadeh also mentioned that it will promote gradual institutionalization and internationalization of the state institution [4]. For those whom join the IOs can gradually regulate their behaviour such as human rights and democratization also mention it will promote gradual institutionalization and internationalization of the state institution. This kind of socialization can change the negative image of being conservative and backward. After joining IOs, the states can establish a consensus over values and norms that will promote the state more likely to cooperate.

\section{THE CASE OF SAUDI ARABIA}

This paper chooses Saudi Arabia as the case to demonstrate the fundamental characters for discussing its accession and compliance to WTO. As far as economics is concerned, oil has largely been as influential in Saudi history and politics as religion. With it, the Kingdom experienced a tremendous physical transformation. Oil has always been the financial engine of the Saudi economy and the main source of the country's export revenues. The particular reason for circumstances is
Saudi Arabia has taken the significant role as the world's second largest oil producer and the world's largest oil expoter, which also controlling the world's second largest oil reserves and the sixth largest gas reserves [5]. Through this kind of system, Saudi has accumulated enormous material wealth. However, Saudi Arabia's non-oil industrial sector has less development, and some types of business are completely restricted for local investors due to religious prohibitions. Another obstacle that is not able to fully exploited to develop its competitive advantage in petrochemicals due to the closed nature of the EU market [6]. WTO accession promises to change this situation, and it will make Saudi Arabia become a major petrochemical producer in the world. This activity demonstrates that the competitor is not possible to invoke WTO regulations to affect the Saudi's exports to the trading partners or setting the trade barriers. All benefits will maximize the competitive advantage in petrochemicals and open access to international markets.

Explaining Saudi Arabia's cultural religions features has been helpful in explaining its political economy. The deep-rooted and flourishing of religious politics is a prominent phenomenon in the history of the Kingdom of Saudi Arabia. In Faisal's account of the Kingdom's political economy, religion played an essential role as an ideology by which the political system could unite the country by transcending in its legitimacy the traditional tribal association [7]. Islam has profound impact of the exact purpose of shaping Saudi Arabia's national identity, idea and interests. Furthermore, the centrality of the royal family and elite autonomy in decision-making appear vindicated in theautocratic monarchy system. In Saudi Arabia, Islamic cultural identity determined what was considered unacceptable behaviour and practice from the ruling family [4]. For example, the king exercises supreme executive and judicial power, and the leadership preference influences their options towards foreign policy. The official religious politics of the Kingdom of Saudi Arabia is dedicated to provides religious political legitimacy to the Saudi ruling family as well.

Ultimately, Saudi Arabia's geopolitical stakes remain high, facing a divided Islamic Middle East and authoritarian rule in domestic politics. The Regional Security Complexity changes in the Gulf creates Instability to the Middle East. Setting regional conflicts between Saudi and Iran as an example, religious denominational differences and doctrinal origins are the main problems. The conflict between the two countries has had important political implications for Syria Yemen, Egypt, Libya and Palestine. And the "special relationship" with the United States will be considered to add the regional security complex. While widespread anti-American sentiment has been appeased, Arab secularism and nationalism continue to reject U.S. involvement [8]. In addition, the U.S. refocusing on the Asia-Pacific region has put Saudi Arabia back at risk of regional conflict. Saudi Arabia is widely questioned 
about human rights and women's employment, and these public opinions have created some obstacles to further Saudi participation in the global political economy integration.

The particular reason for analysing Saudi Arabia's international politics economy is of significance, the circumstance of which provides an exceptional example for explaining its accession to WTO. Through multiple perspectives, we will modify our further study towards the distinctive reasons for a country joining IOs.

\section{THEORETICAL APPROACH TO SAUDI'S ACCESSION}

For the fourth part of the essay, we will explain how the constructivist theory can be applied to Saudi Arabia's accession to the WTO and its level of compliance since 2015. As mentioned in the last part of the essay, we know that constructivists believe that as countries make decisions on the international stage, it is led by both the logic of consequences and the logic of appropriateness. According to the first Director-General of the WTO, Peter Sutherland, the WTO becomes a platform for countries that values economic liberty and free trade, where it would demonstrate its benefits and then inspire countries such as Saudi Arabia to participate in the WTO [9]. As a result, we know that the WTO itself is a valuebased organization.

As for the identity of Saudi Arabia, we must not forget that while it is one of the most powerful nations in the Middle East, it is also a very religious government with high commitments to Wahhabism. The impact of their Islamic identity can be traced in the process of the negotiation process. Although the Saudi Arabian government did try to liberalize its trade and allow investment in some of their domestic sectors, their regulations, even after the negotiations with the WTO, is still far more strict than other new members of the WTO, such as China and Cambodia [10]. This is not an unusual phenomenon within the Muslim world. In fact, according to former US ambassador to Saudi Arabia Chas Freeman, there is an intrinsic contradiction between the idea of an open market and globalization and traditional Islamic principles [10]. As a result, he seriously doubts to what extend will the Saudi Arabians implement the WTO rules, at least in the short term. From the suspicion proposed by Ambassador Freeman, it is identifiable that Saudi Arabia's decision-making process is still considerably influenced by its Islamic identity, even though the liberalization of certain sectors, such as finance, will boost its economic development.

Moreover, because of Saudi Arabia's absolute monarch system, it implies that the decision by its leaders is much more significant than the traditional western democratic countries. This brings us to another significant characteristic of constructivism, where it does not only focus on the systemic level of analysis like neorealism or neoliberalism but would go down to the individual level. Many scholars, and eminent international organization officials such as Sutherland and Professor Malik Dahlan, have all pointed out the significance of King Abdullah in the process of WTO accession, where specific empirical evidence would be provided in the next section [11].

Taking all elements into consideration, many scholars propose the fact that the decision of joining the WTO, instead of being perceived as simply a maximization of national interest, there is an intertwin between the logic of consequence and logic of appropriation. There are 2 identities that the Saudi government has in this process. First is the advocate for a more liberalized and diverse economy, for it is not only beneficial for Saudi Arabia itself, but it is also because of the wave of economic liberalization to developing countries in the 1990's, where it is widely suspected that the Saudi leaders, especially King Abdullah himself, is heavily influenced by such value. Moreover, its deep-rooted Islamic belief has also limited its process of economic liberalization, where only parts of sectors are opened (along with many Islam-centric restrictions). In the next section, there will also be global norms and value shifts, the Saudis would behave differently in terms of compliance within the international society.

\section{AN ANALYSIS OF THE EMPIRICAL EXAMPLE ABOUT SAUDI ARABIA}

the essay will then offer an analysis of the empirical example about Saudi Arabia, including the accession and compliance to WTO. As demonstrated before, in an era when most of the countries across the world are engaged in integrating their economies, it becomes very difficult for nations to remain in isolation by barring other countries from entering its own market. Therefore, one of Saudi's objectives is to obtain the WTO membership, which requires Saudi Arabia to liberalize its economy in a large scale. We would like to introduce Saudi's compliance mainly in two aspects: opening up its market to foreign players, although still in a quite limited level due to religious and political reasons; and secondly undertaking a restructuring program of its legal system, especially those relating to intellectual properties.

For the first aspect, it should be made clear that Saudi Arabia has well understood the importance of increasing foreign participation in its economy and its implications on the stability of its economy. Thus, during the tedious, countless negotiations with WTO, under the pressure of EU and US, Saudi step by step reduced restrictions of foreign investment as well as tariffs on imports of goods. In the revised document released in 2005, tariffs of most agricultural products have slumped to around $12 \%$ [12]. However, there are some sectors remain prohibited with the consideration of traditional Muslims, such as the 
import of alcohol and pork, and we shall remember its limitations on stock markets as well. Apart from these, compliance is especially worth noting. Foreign investments are no longer so difficult as before: they can take one of these forms- $i$. a joint venture in partnership with a Saudi firm, and ii. a fully foreign owned company. For example, 2005's report said in terms of market access, "non-Saudi participation in the joint-stock company in Saudi Arabia is permitted up to $60 \%$ from the date of accession." Besides, to ensure the prospect after the accession, the Saudi Arabian General Investment Authority was established in 2000.

To some extent, it serves both as a promoter and a regulator of legal reforms, though its original mandate, as King Abdullah demanded, is to attract investment by creating a pro-business, investment-friendly environment. Abdullah recognizes that the Kingdom's economy requires liberalization, and in the year of 2005, he put forward the idea of new Economic Cities as a kind of free zone throughout the world, and SAGIA became the most important regulatory body of these cities. We can see that individuals really play a role in the development of a country, especially when we take Saudi's religious-political situation into consider. Actually, kings also realized such conditions, and $\mathrm{MbS}$ was firstly named the chair of the Council for Economic and Development Affairs, once after King Salman became the King in 2015. This new committee is the kingdom's main economic policymaking agency.

For legal restructuring, Saudi Arabia took additional measures towards greater compliance with the WTO's Agreement on Trade Related Intellectual Property Rights (TRIPS). The new Patents Law enacted by Royal Decree provides specific provisions on patents, industrial designs, etc. In the paper about TRIPS, Saudi gives a macro timeline for its subsequent steps aiming to consolidate the protection of intellectual properties and promises to enhance the transparency of new laws.

However, the protection can be vulnerable once faced with other national interests. In 2017, considering the competing relation with Qatar, Saudi Arabia imposed a scheme of diplomatic, political, and economic measures against Qatar, including beIN Media Group LLC and affiliates ("beIN"). Saudi Arabia has prohibited beIN from broadcasting its content in Saudi Arabia and soon created a pirated broadcast, "beoutQ". Until now, the case is still underway. Because in former case Dispute Settlement Body backed Qatar, Saudi proposed its decision to appeal. What's furthermore, as we are well aware, the Appellate Body of the WTO is currently unavailable to resolve appeals. So, they are still in a dilemma. Here we can see that although constructivism may make a difference in the realm of international relationships, it would not always be the favourite of governors. In some ways, international organizations cannot be the optimal solution for the dispute settlement mechanism.

\section{SAUDI ARABIA'S PROSPECT IN WTO}

It is of great importance to predict the future tendency of Saudi Arabia in WTO. Such prediction might effectively and deeply influence the WTO's future policy making, and even will impact on the base of inter-state economic cooperation. Therefore, in order to avoiding casual judgement, the prediction should be comprehensive enough that not only bases on Saudi's existing practices in WTO recently, also should not overlook the intrinsic features possessed by Saudi Arabia which may negatively affect the trend.

\subsection{The Consideration of Saudi Arabia's Short-term Performance}

The reality is that since 2003 Saudi Arabia has performed relatively positively in response to and engage in the WTO. WTO has examined and evaluated Saudi's trade policies in 2012, 2016 and 2021, respectively. The review of trade policy demonstrated that until 2021, Saudi's economy still heavily depends on the oil section, but the economic liberalization efforts have been gradually made and shown, including more liberal policies, property rights protection, and labor forces improvements. It cannot be denied that all these efforts have shown Saudi's attempts of expanding and enhancing the competitiveness on non-oil sectors, and further to achieve its purpose of diversifying the patterns of economic growth. In 2021's policy review, the related reports have indicated a concept 'Vision 2030' that was advocated by Saudi [13]. The 'Vision 2023' has revealed a considerable blueprint in Saudi's future, and various economic and societal reforms, such as the improvement of women's rights, and the liberalization in certain economic sectors, are clearly influenced by Saudi Arabia's accession to the WTO [13]. Hence, the 'Vision 2030' have shown the ambition of achieving all-round progress of Saudi Arabia and also the determination of more positive interactions in the WTO.

In addition, after Saudi Arabia's accession to WTO, there is no other trade dispute, the conflicts with Qatar during these years [14]. In other words, the less disputes methods, the more Saudi Arabia's compliance to the rules and policies made by the WTO. Moreover, Saudi Arabia always plays the role as the third party in dispute settlement. Saudi Arabia would promote the resolution of trade disputes cautiously by reasonably legally analyse the situation between states with the consideration of whether the behaviour is consistent with self-policies, especially the trade policies in a regional sphere [15]. Saudi Arabia is also a member of a regional economic organization- Gulf Cooperation Council (GCC). GCC's trade policies will effectively affect the direction and 
preference, and further the fairness of Saudi Arabia while dealing with other states' disputes. Many parts of the policies of GCC are positively matched with the WTO stipulations, and the consistency has resulted in Saudi Arabia become a relatively decent role to facilitate equal resolutions.

\subsection{The Prediction of Saudi Arabia's Long- term Direction}

The practical actions adopted by Saudi Arabia may influence the judgment of the prospect of Saudi Arabia. These actions show the potential of long-term membership in the WTO. However, it is not enough to predict the future trends only through these changes and even these ambitions. Saudi Arabia's politics and religion these substantial elements require to be considered. A political regime of monarchy centralize on the royal family has such strength to determine policies adoptions and control the future direction of the whole state. The absolute power possessed by a small group of people can generate a considerable change in a short period of time. Royal decision of liberalization and even the accession and compliance to WTO can gradually form as Saudi's policies and the interests in a short-term. Mohammed bin Salman Al Saud (MBS), who will become the king of the Saudi Arabia, has implemented some reforms to reduce the religious constraints and move to a more liberal and exoteric orientation [16]

Nevertheless, it also increases the uncertainty and instability of maintaining. The king of Saudi Arabia is not eternally, hence it is hard to ensure the consistency and stationarity of liberalizing orientation. Meanwhile, it will be hard to guarantee the stability of one leader's thoughts as well. Thoughts may possibly be influenced by selfinterests and external environment and has intrinsic changes immediately. Saudi Arabia's situation is complicated, due to the 'dual identity' which is constructed by two kinds of social identity. On the one hand, Saudi Arabia pursues to liberalize the domestic economy and positively respond to globalization, and reasons can be derived from the adequate acquisitions of participating in the international world. While on the other hand, Saudi Arabia is still under the powerful conservative Muslim ideology, which can constitute as identity and may affect the social norms, the policy setting and implementation. Pure Muslims has restricted many aspects of life. Such as the restrictions of women's rights and the constraints of import regulations. Therefore, the political and religious factors may also increase the unpredictability of estimating the achievement of the goal of 'Vision 2030'. The preference and interests of Saudi Arabia may change over time due to different interactions, new information and variational international. Therefore, it is not wise to define Saudi's future direction in WTO readily. The prospect of Saudi Arabia is still unpredictable.

\section{CONCLUSION}

The essay has been divided into five sections with the aim of fully analyse Saudi Arabia's behaviour towards the WTO from a specific constructivist perspective. In summary, the essay firstly has focused on the constructivist rationale to explain some constructivist assumptions theoretically. Then has put constructivism on the case of Saudi Arabia to substantially explain that factors such as the power of the individual and the strength of Muslim identity will influence Saudi Arabia's entry into the WTO. After that, there are some empirical findings have been mentioned, including the 'dual identity' of Saudi Arabia to further prove and analyse the accession and compliance to the WTO. Following that, the essay has predicted the prospect of Saudi Arabia in the WTO, drawing out the conclusion that Saudi's future is still unpredictable. By doing so, the essay managed to answer the researcher's question from a more long-term, broaden and critical sight.

The essay not only deepened our understanding of how to apply the constructivist theory on a specific case like Saudi Arabia, but also helped us understand the factors that influence Saudi's behaviour towards and in WTO, and even helped predict the future tendency of Saudi which may importantly affect the WTO to implement some relative policies in the future and treat Saudi more critically and neutrally. In addition, it has provided a more broaden view not merely restricts in the Saudi Arabia itself, but more on the issue of the Middle East. Evaluating the specific example of Saudi Arabia would help to solve the common issues in the whole region.

Furthermore, the essay has several limitations that cannot be ignored. The analysis may be incomplete due to lack of adequate data, quantitative analysis, and the specific cultural recognition. What methodology mainly utilized to explain and even predict the Saudi's behaviour is theoretical analysis combining with some empirical evidences, which means there may be limited in a quantitative way with enough or even adequate data. Moreover, it will also exist an issue of different cultural recognition. The authors may lack sufficient Saudi's cultural cognition which may generate incomplete information and further to negatively affect the argument's exactitude. The essay merely utilizes a single case, and this may provide limited explanations.

From the limitations that have been mentioned before, there are some new future research directions. Further studies can more focus on the data sphere to enrich the empirical evidence and provide a more comprehensive perspective, and the future studies can focus on other cases, not only the case of Saudi, to further evaluate and apply the constructivism on more practical problems. Also, to fully understand the phenomenon, it is worthwhile to explore other perspectives and reasons. It 
can also analyse from the perspective of neo-classical realism, which both focus on the international sphere and domestic politics.

\section{REFERENCES}

[1] Karraboo, J. \& Ray, J. L. 2017, Global Politics. Wadsworth Publishing, Boston, Massachusetts.

[2] Bello, H. J., 2017, Islamic Identity, Oil and Global insecurity - Affirming Social Constructivism in the 21st Century, global politics, 6(1), 91-98.

[3] Checkel, J., 2015, International Institutions and Socialization in Europe: Introduction and Framework. International Organization, 59(4), 801826.

[4] Mohammazadeh, B., 2019, Beyond royal politics: state transformation and foreign policy in Saudi Arabia. Third World Quarterly, 40(8), 1571-1589.

[5] Ramady, M. A., 2010, The Saudi Arabian Economy: Policies, Achievements, and Challenges. International Economics, 32-41

[6] Rao, D.N. 2001, Saudi Arabia's Accession to WTO: Future Challenges

[7] Faisal, G.,2012, Accession to the World Trade Organization: factors shaping the case of Saudi Arabia's accession (1985-2005). International Relations, 118-139

[8] Subhan, T.,2003, US-Saudi Arabia Relations: Coming of Age. Economic and Political Weekly. 38(37):3885-3887

[9] Sutherland, P. D. (2008). Transforming nations how the WTO boosts economies and opens societies. Foreign Affairs, 87(2), 125-137.

[10] Clatanoff, W., Parlin, C., Jordan, R., Kestenbaum, C., Seznec, J. (2006). Saudi Arabia's Accession to the WTO: Is a "Revolution Brewing?" Middle East Policy, 13(1), 1-23

[11] Dahlan, M. R., \& Zedan, H. (2009). Saudi Arabia: Royal Succession Reforms, Judicial Reforms, SAGIA Economic Cities Initiative, and WTO Accession. Yearbook of Islamic and Middle Eastern Law, 14, 339-346.

[12] WTO, 2005. Schedule of Specific Commitments in Services List of Article II MFN Exemptions Addendum. Retrieved from https://docs.wto.org/dol2fe/Pages/SS/directdoc.asp $\mathrm{x}$ ?filename $=\mathrm{q}: / \mathrm{WT} / \mathrm{ACCSPEC} / \mathrm{SAU} 7 \mathrm{~A} 2 . \mathrm{pdf} \& O p e$ $\mathrm{n}=$ True

[13] WTO, 2021. Trade Policy Review: Saudi Arabia. Retrieved https://www.wto.org/english/tratop_e/tpr_e/tp507_ e.htm.

[14] WTO, 2017. Saudi Arabia- Measures Relating to Trade in Goods and Services, And Trade-Related Aspects of Intellectual Property Rights. Retrieved from https://www.wto.org/english/tratop_e/dispu_e/cases _e/ds528_e.htm

[15] Alamri, M., 2017, Saudi Arabia's Role as Third Party in WTO Anti-Dumping Conflicts. International Journal of Business and Social Science, 8(6), 72-79.

[16] Spencer, R.,2017. Heir's modernising vision risks conservative discontent. Retrieved from https://www.thetimes.co.uk/article/heir-smodernising-vision-risks-conservative-discontents0cwgjxm9 